\title{
Perbedaan Perilaku Masyarakat dalam Pelaksanaan Nagari Siaga di Nagari Padang Laweh dan Nagari Kubang Putiah Kabupaten Agam
} The Difference of Community Behaviour In Implementation of Nagari Siaga Between Nagari Padang Laweh and Nagari Kubang Putiah In Agam District

\author{
Putri Nilam Sari, Rizanda Machmud, Nopriadi
}

\section{Program Studi Ilmu Kesehatan Masyarakat FK UNAND}

\begin{abstract}
ABSTRAK
Jumlah Nagari Siaga di Propinsi Sumatera Barat pada akhir tahun 2008 adalah 2.152. Akan tetapi angka ini masih belum mencapai target yaitu 3.317 Nagari Siaga. Terlaksananya Nagari Siaga memerlukan dukungan penuh dari masyarakat sebagai penggerak Nagari Siaga yang dimulai dari pemahaman dan sikap positif akan kesehatan itu sendiri. Penelitian ini dilakukan untuk mengetahui perbedaan perilaku masyarakat dalam pelaksanaan Nagari Siaga di Nagari Padang Laweh dan Nagari Kubang Putiah Kabupaten Agam. Penelitian ini menggunakan desain Cross Sectional Study, dengan jumlah sampel 84 kepala keluarga pada kedua nagari. Variabel dependen pada penelitian ini adalah Nagari Siaga dan variabel independen adalah pengetahuan, sikap dan tindakan. Analisa bivariat dilakukan dengan uji Chi Square $\left(X^{2}\right)$ dengan $\alpha=0,05$. Hasil analisa menunjukan adanya hubungan yang signifikan antara variabel pengetahuan dan tindakan terhadap pelaksanaan Nagari Siaga dengan nilai $\mathrm{p}$ value 0,00 . Terdapat perbedaan pengetahuan dan sikap antara kedua nagari dimana pengetahuan dan tindakan masyarakat di Nagari Kubang Putiah lebih baik daripada Nagari Padang Laweh. Variabel sikap tidak dapat diujikan karena sikap pada kedua nagari seluruhnya (100\%) positif. Perlu sosialisasi kepada masyarakat mengenai pentingnya kesehatan dan program Nagari Siaga di Nagari Padang Laweh agar program Nagari Siaga dapat berjalan optimal seperti Nagari Kubang Putiah. Bagi Nagari Kubang Putiah perlu dikembangkan program Nagari Siaga secara terus menerus. Partisipasi lintas sektoral perlu ditingkatkan untuk keberhasilan program Nagari Siaga.
\end{abstract}

Kata Kunci: Perilaku, Pelaksanaan Nagari Siaga, Kabupaten Agam

\section{ABSTRACT}

The number of Nagari Siaga in West Sumatera Province at the end of the year 2008 is 2.125. However this number has not been reached the target yet that are 3.317 Nagari Siaga. The implementation of Nagari Siaga requires a full support of the community as the major driver that is initiated by the understanding and positive attitude towards health itself. The aim of this research is knowing about the difference of community behaviour in implementating Nagari Siaga between Nagari Padang Laweh and Nagari Kubang Putiah in Agam District. This study used cross sectional study design, with a total sample of 84 head families in both villages. Dependent variable in this study is Nagari Siaga and independent variable are knowledge, attitude and practice. Bivariate analysis was done by Chi Square $\left(X^{2}\right)$ with $\alpha=0,05$. The analysis shows significant relationship between the variables of knowledge and practice on implementation of Nagari Siaga with $p$ value of 0,00. There are differences in knowledge and attitudes between the two villages. Knowledge and community practices in Nagari Kubang Putiah were better than Nagari Padang Laweh. Attitude variables can not be tested because the attitude in both villages is completely (100\%) positive. It needs sosialization to the community about the importance of health and Nagari Siaga program in Nagari Padang Laweh, so that the program can be run optimally as well as Nagari Kubang Putiah. For Nagari Kubang Putiah, Nagari Siaga program should be developed continiously. Cross-sector participation should be increased to the success of Nagari Siaga program.

Keywords: Behaviour, Implementation of Nagari Siaga, Agam Distric

\section{PENDAHULUAN}

Indonesia memiliki kurang lebih 69.000 desa. Menurut perhitungan, terdapat kurang lebih 12.000 desa yang sama sekali tidak memiliki akses terhadap pelayanan kesehatan. Desa-desa ini akan diprioritaskan menjadi Nagari Siaga. Di Sumatera Barat program Nagari Siaga disebut dengan Nagari Siaga. Jumlah Nagari Siaga di Propinsi Sumatera Barat tahun 2007 yaitu 209 nagari dan pada akhir tahun 2008 meningkat signifikan menjadi 2.152 nagari, akan tetapi masih belum mencapai target yaitu 3.317 nagari yang menjadi Nagari Siaga.

Penelitian yang dilakukan oleh Ane di Kecamatan Rao Utara (2009), didapatkan bahwa pelayanan kesehatan yang diharapkan oleh masyarakat jorong belum terlaksana karena masih banyaknya kekurangan pada tenaga, dana, sarana dan prasarana 
Hal ini menggambarkan masih belum terlaksananya kegiatan pelaksanaan Nagari Siaga secara maksimal.

Bloom (1908) menyebutkan bahwa terdapat tiga hal yang merupakan domain perilaku. Hal tersebut adalah tingkat Pengetahuan, Sikap dan Tindakan yang membentuk perilaku seseorang mengenai kesehatan. Pelaksanaan Nagari Siaga memerlukan dukungan penuh dari masyarakat sebagai penggerak yang dimulai dari pemahaman dan sikap positif akan kesehatan itu sendiri. Masyarakat diharapkan tahu dan mau bekerjasama dalam dalam mengembangkan Nagari Siaga. Dukungan yang diharapkan dari masyarakat dapat berupa dukungan moral, finansial atau material yang sesuai dengan kesepakatan dan persetujuan masyarakat dalam rangka pengembangan Nagari Siaga.

Pada tahun 2006, Bupati Kabupaten Agam menunjuk Nagari Padang Laweh sebagai Nagari Siaga. Sarana kesehatan untuk menunjang program ini adalah 1 buah Pos Kesehatan Nagari (Poskesri), 3 buah Pondok Bersalin Desa (Polindes) dan 2 buah Pos Pelayanan Terpadu (Posyandu). Nagari ini telah memiliki kader posyandu yang dilatih 2 kali setahun.

Berdasarkan wawancara pendahuluan dengan sekretaris nagari dan pembina Nagari Siaga didapatkan keterangan bahwa kegiatan Nagari Siaga belum terlaksana dengan optimal. Di nagari ini belum dilaksanakan pertemuan tetap dalam kegiatan Nagari Siaga. Masih sedikit masyarakat yang mau ikut dalam perkumpulan untuk membahas kegiatan Nagari Siaga, masih jarang masyarakat yang bersedia mengumpulkan dana swadaya kesehatan, dan banyak dari ibu yang tidak lagi membawa anaknya ke posyandu setelah imunisasi lengkap dilaksanakan.

Pada bulan Februari tahun 2007, Bupati Agam menunjuk Nagari Kubang Putiah sebagai Nagari Siaga dengan memberikan surat penugasan kepada wali nagari. Sarana kesehatan untuk menunjang program ini adalah 2 puskesmas pembantu yang salah satunya adalah poskesri dan 25 buah posyandu. Nagari ini telah memiliki kader 1 orang setiap jorongnya yang telah dilatih di puskesmas kecamatan.

Berdasarkan wawancara pendahuluan dengan wali nagari dan pembina Nagari Siaga didapatkan keterangan bahwa kegiatan Nagari Siaga di Nagari Kubang Putiah sudah berjalan dengan baik. Kubang Putiah sering dijadikan tujuan studi banding dan percontohan oleh berbagai daerah dan instansi diantaranya Dinas Kesehatan Provinsi Sumatera Barat, Deputi Cawapres bagian Kesehatan Rumah Tangga, Propinsi Kalimantan Barat, Kabupaten Kampar
Propinsi Riau, dan Nagari Aia Bangih Kabupaten Pasaman Barat.

Nagari ini telah memiliki masyarakat yang peduli untuk mencapai tujuan Nagari Siaga. Hal ini terbukti dengan adanya pertemuan khusus dalam membahas kegiatan-kegiatan Nagari Siaga, adanya program 'kendaraan siaga' yaitu seluruh masyarakat bersedia jika suatu saat kendaraannya dibutukan jika ditemukan kejadian gawat darurat. Salah satunya adanya 'ambulance siaga' nagari yang merupakan sukarela masyarakat. Masyarakat juga mempunyai pembiayaan kesehatan masyarakat yang disebut masyarakat setempat sebagai 'dana sehat' untuk program Nagari Siaga. Organisasi lain yang dimiliki nagari Kubang Putiah dalam menunjang kegiatan Nagari Siaga yaitu adanya Persatuan Donor Darah Indonesia.

Tujuan penelitian ini adalah untuk mengetahui perbedaan perilaku masyarakat dalam pelaksanaan Nagari Siaga di Nagari Padang Laweh dan Nagari Kubang Putiah Kabupaten Agam.

\section{METODE}

Desain penelitian ini adalah Cross Sectional Study. Penelitian ini untuk mengetahui hubungan antara variabel independen yaitu prilaku masyarakat (tingkat pengetahuan, sikap dan tindakan) dengan variabel dependen (pelaksanaan nagari siaga). Populasi penelitian ini adalah kepala keluarga yang berada di Nagari Padang Laweh sebanyak 676 KK, dan Kubang Putiah sebanyak $1.765 \mathrm{KK}$, sehingga jumlah populasi seluruhnya sebanyak 2.441 KK. Dari perhitungan rumus didapatkan besar sampel 84 orang. Teknik pengambilan sampel adalah Proportional Stratified Random Sampling. yaitu sampel dibagi untuk tiap-tiap jorong, dan untuk tingkat jorong pengambilan sampel dilakukan dengan Simple Random Sampling.

Pengumpulan data primer dilakukan dengan wawancara dan observasi. Untuk melihat hubungan antara variabel independen dan variabel dependen digunakan uji Chi Square $\left(\mathrm{X}^{2}\right)$ dengan tingkat kepercayaan $95 \%$.

\section{HASIL}

\section{Perbedaan Tingkat Pengetahuan dengan Pelaksanaan Nagari Siaga}

Frekuensi responden yang memiliki pengetahuan tinggi lebih banyak di Nagari Kubang Putiah $(95,2 \%)$ dibandingkan dengan Nagari Padang Laweh $(52,4 \%)$. (lihat gambar 1) 


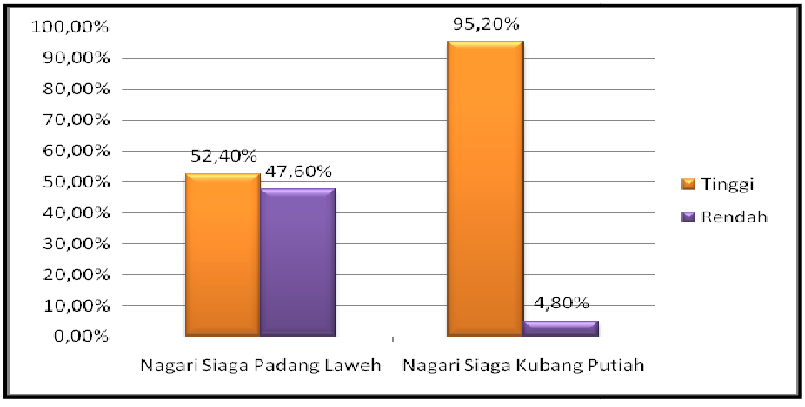

Gambar 1. Distribusi Frekuensi Responden Menurut Tingkat Pengetahuan

Berdasarkan hasil uji statistik terdapat hubungan yang bermakna antara tingkat pengetahuan masyarakat pada Nagari Padang Laweh dan Nagari Kubang Putiah dengan pelaksanaan Nagari Siaga $\left(\mathrm{p}_{\mathrm{v}}=\right.$ 0,000), OR: 18,2 dengan $95 \%$ CI $(3,9-85,1)$, artinya tingkat pengetahuan yang rendah berpeluang 18,2 kali untuk kurang berjalannya pelaksanaan Nagari Siaga dibandingkan dengan tingkat pengetahuan yang tinggi. (lihat tabel 1)
Di Nagari Padang Laweh masih banyak masyarakat yang tidak mengetahui mengenai manfaat imunisasi, fungsi pemimpin dan tokoh masyarakat dalam program Nagari Siaga, manfaat dari Pos Kesehatan Nagari (Poskesri), menu gizi seimbang, dan jarak jamban dengan sumber air minum. Pada Nagari Kubang Putiah, masih banyak masyarakat yang tidak mengetahui pembiayaan kesehatan dalam program Nagari Siaga, tempat pembuangan tinja yang baik menurut syarat kesehatan dan manfaaat dari musyawarah masyarakat nagari. (lihat tabel 2)

Tabel 1.

Distribusi Responden berdasarkan Tingkat Pengetahuan Masyarakat terhadap Pelaksanaan Nagari Siaga

\begin{tabular}{ccccccc}
\hline \multirow{2}{*}{$\begin{array}{c}\text { Tingkat } \\
\text { Pengetahuan }\end{array}$} & \multicolumn{4}{c}{ Nagari Siaga } & \multirow{2}{*}{$\begin{array}{c}\text { Padang } \\
\text { Laweh }\end{array}$} & \multicolumn{2}{c}{$\begin{array}{c}\text { Kubang } \\
\text { Putiah }\end{array}$} & Jumlah \\
\cline { 2 - 6 } & $\mathbf{f}$ & $\mathbf{\%}$ & $\mathbf{F}$ & $\mathbf{\%}$ & $\mathbf{f}$ & $\mathbf{\%}$ \\
\hline Rendah & 20 & 47,6 & 2 & 4,8 & 22 & 26,2 \\
Tinggi & 22 & 52,4 & 40 & 95,2 & 62 & 73,8 \\
Jumlah & $\mathbf{4 2}$ & $\mathbf{1 0 0}$ & $\mathbf{4 2}$ & $\mathbf{1 0 0}$ & $\mathbf{8 4}$ & $\mathbf{1 0 0}$ \\
\hline $\mathrm{X}^{2}=17,8$ & $\mathrm{df}=1$ & $\mathrm{p}_{\mathrm{v}}=0,000$ & $\mathrm{OR}=18,2$ &
\end{tabular}

Tabel 2.

Distribusi Pertanyaan Pengetahuan yang Dijawab Benar pada Nagari Padang Laweh dan Kubang Putiah

\begin{tabular}{|c|c|c|c|c|c|}
\hline \multirow[t]{2}{*}{ Pertanyaan Pengetahuan } & \multicolumn{2}{|c|}{$\begin{array}{c}\text { Nagari Siaga } \\
\text { Padang Laweh }\end{array}$} & \multicolumn{2}{|c|}{$\begin{array}{c}\text { Nagari Siaga } \\
\text { Kubang Putiah }\end{array}$} & \multirow[t]{2}{*}{$\Delta$} \\
\hline & f & $\%$ & f & $\%$ & \\
\hline Manfaat imunisasi & 4 & 9,5 & 23 & 54,8 & 45,3 \\
\hline Fungsi pemimpin dan tokoh masyarakat dalam program Nagari Siaga & 18 & 42,9 & 34 & 81 & 38,1 \\
\hline Oleh siapa persalinan sebaiknya dilakukan & 26 & 61,9 & 42 & 100 & 38,1 \\
\hline Manfaat dari Pos Kesehatan Nagari (Poskesri) & 19 & 45,2 & 34 & 81 & 35,8 \\
\hline Salah satu menu gizi seimbang & 20 & 47,6 & 32 & 76,2 & 28,2 \\
\hline Penyakit utama yang disebabkan oleh rokok & 30 & 71,4 & 41 & 97,6 & 26,2 \\
\hline Jarak jamban dengan sumber air minum & 16 & 38,1 & 27 & 64,3 & 26,2 \\
\hline Manfaat kendaran siaga dari masyarakat & 27 & 64,3 & 30 & 71,4 & 7,1 \\
\hline Manfaat olahraga dengan teratur & 34 & 81 & 37 & 88,1 & 7,1 \\
\hline $\begin{array}{l}\text { Harapan terhadap masyarakat jika ditemukan penyakit menular dan } \\
\text { tidak menular yang berbahaya }\end{array}$ & 40 & 95,2 & 41 & 97,6 & 2,4 \\
\hline Manfaat hanya memberikan ASI selama 6 bulan pertama umur bayi & 41 & 97,6 & 42 & 100 & 2,4 \\
\hline Penyakit yang disebabkan oleh jentik nyamuk & 32 & 76,2 & 32 & 76,2 & 0 \\
\hline Lantai rumah yang belum sehat & 42 & 100 & 41 & 97,6 & $-2,4$ \\
\hline Manfaat dari musyawarah masyarakat nagari & 34 & 81 & 27 & 64,3 & $-16,7$ \\
\hline Tempat pembuangan tinja yang baik menurut syarat kesehatan & 33 & 78,6 & 26 & 61,9 & $-16,7$ \\
\hline Pembiayaan kesehatan masyarakat dalam program Nagari Siaga & 23 & 54,8 & 15 & 35,7 & $-19,1$ \\
\hline
\end{tabular}

Perbedaan Sikap dengan Pelaksanaan Nagari Siaga Untuk variabel sikap tidak dapat dilakukan uji statistik karena tidak ditemukan responden yang mempunyai sikap negatif.
Perbedaan Tindakan dengan Pelaksanaan Nagari Siaga

Frekuensi responden yang memiliki tindakan baik lebih banyak pada Nagari Kubang Putiah (85,7\%) dibandingkan Nagari Padang Laweh (40,5\%) (lihat gambar 2). 
Berdasarkan hasil uji statistik terdapat hubungan yang bermakna antara tindakan masyarakat pada Nagari Padang Laweh dan Nagari Kubang Putiah dengan Pelaksanaan Nagari Siaga, $\left(\mathrm{p}_{\mathrm{v}}=0,000\right)$, OR: 8,8 dengan $95 \%$ CI $(3,053-25,504)$, artinya tindakan kurang baik berpeluang 8,82 kali untuk kurang berjalannya pelaksanaan Nagari Siaga dibandingkan dengan tindakan yang baik. (lihat tabel 4)

Masyarakat di Nagari Padang Laweh masih banyak yang tidak memakai jamban dengan model leher angsa, tidak berolah raga secara teratur, tidak memberikan ASI saja selama 6 bulan, tidak menguras bak mandi sekali seminggu, tidak memakan sayur dan buah setiap hari, dan merokok di dalam rumah. Pada Nagari Kubang Putiah tenaga kesehatan belum bisa dikunjungi 24 jam dalam keadaan darurat dan masih banyak anggota keluarga yang merokok di dalam rumah. (lihat pada tabel 5)

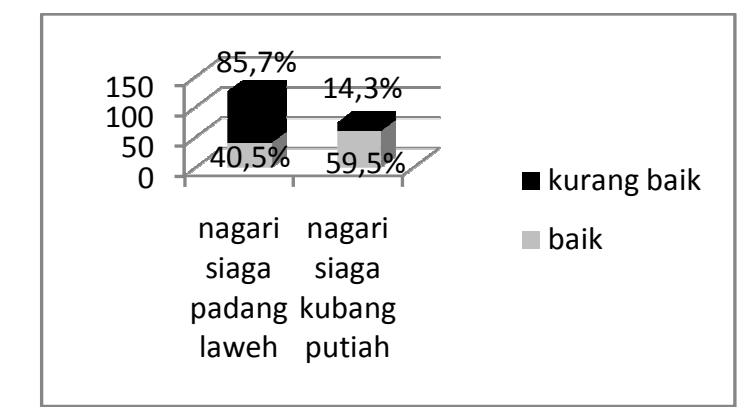

Gambar 2. Distribusi Frekuensi Responden Menurut Tindakan

Tabel 4

Distribusi Responden berdasarkan Tindakan Masyarakat terhadap Pelaksanaan Nagari Siaga

\begin{tabular}{cccccccc}
\hline \multirow{2}{*}{ Tindakan } & \multicolumn{9}{c}{ Nagari Siaga } & \multirow{2}{*}{$\begin{array}{c}\text { Padang } \\
\text { Laweh }\end{array}$} & \multicolumn{2}{c}{$\begin{array}{c}\text { Kubang } \\
\text { Putiah }\end{array}$} & \multirow{2}{*}{ Jumlah } \\
& \cline { 2 - 6 } & $\mathbf{f}$ & $\mathbf{\%}$ & $\mathbf{f}$ & $\mathbf{\%}$ & $\mathbf{f}$ & $\mathbf{\%}$ \\
\hline Kurang Baik & 25 & 59,5 & 6 & 14,3 & 31 & 36,9 \\
Baik & 17 & 40,5 & 36 & 85,7 & 53 & 63,1 \\
Jumlah & $\mathbf{4 2}$ & $\mathbf{1 0 0}$ & $\mathbf{4 2}$ & $\mathbf{1 0 0}$ & $\mathbf{8 4}$ & $\mathbf{1 0 0}$ \\
\hline $\mathrm{X}^{2}=16,6$ & $\mathrm{df}=1$ & \multicolumn{3}{c}{$\mathrm{p}_{\mathrm{v}}=0,000$} & \multicolumn{3}{c}{ OR $=8,82$}
\end{tabular}

Tabel 5.

Distribusi Pertanyaan Tindakan yang Dijawab Benar pada Nagari Padang Laweh dan Kubang Putiah

\begin{tabular}{|c|c|c|c|c|c|}
\hline \multirow[t]{2}{*}{ Pertanyaan Tindakan } & \multicolumn{2}{|c|}{$\begin{array}{c}\text { Nagari Siaga } \\
\text { Padang Laweh }\end{array}$} & \multicolumn{2}{|c|}{$\begin{array}{l}\text { Nagari Siaga } \\
\text { Kubang } \\
\text { Putiah }\end{array}$} & \multirow[t]{2}{*}{$\Delta$} \\
\hline & f & $\%$ & f & $\%$ & \\
\hline Jamban memakai model leher angsa. & 13 & 31,0 & 31 & 73,8 & 42,8 \\
\hline Berolahraga secara teratur. & 14 & 33,3 & 31 & 73,8 & 40,5 \\
\hline Tokoh masyarakat memberikan contoh teladan tentang hidup sehat. & 25 & 59,5 & 40 & 95,2 & 35,7 \\
\hline $\begin{array}{l}\text { Setiap anggota keluarga yang mempunyai bayi, memberikan ASI saja sampai } \\
\text { bayi berumur } 6 \text { bulan. }\end{array}$ & 21 & 50 & 31 & 73,8 & 23,8 \\
\hline Menguras bak mandi sekali seminggu. & 18 & 42,9 & 28 & 66,7 & 23,8 \\
\hline Lantai bukan dari tanah & 28 & 66,7 & 37 & 88,1 & 21,4 \\
\hline Makan sayur dan buah setiap hari. & 19 & 45,2 & 27 & 64,3 & 19,1 \\
\hline Menyisihkan dana untuk biaya kesehatan. & 22 & 52,4 & 25 & 59,5 & 7,1 \\
\hline Tidak ada anggota keluarga yang merokok di dalam rumah. & 18 & 42,9 & 21 & 50 & 7,1 \\
\hline $\begin{array}{l}\text { Mengikuti musyawarah masyarakat seperti kelompok yasinan, majelis taklim, } \\
\text { kelompok karang taruna }\end{array}$ & 29 & 69 & 30 & 71,4 & 2,4 \\
\hline Setiap anggota keluarga yang melahirkan, persalinan ditolong oleh bidan. & 41 & 97,6 & 41 & 97,6 & 0 \\
\hline Pernah memanfaatkan Pos Kesehatan Nagari atau puskesmas pembantu. & 40 & 95,2 & 40 & 95,2 & 0 \\
\hline Setiap balita memiliki imunisasi lengkap. & 39 & 92,9 & 37 & 88,1 & $-4,8$ \\
\hline Jarak sumber air bersih dengan septic tank lebih dari 10 meter & 33 & 78,6 & 30 & 71,4 & $-7,2$ \\
\hline $\begin{array}{l}\text { Melaporkan kepada petugas kesehatan saat ditemukan masalah kesehatan } \\
\text { seperti diare, gizi kurang, demam berdarah, rabies, dan penyakit berbahaya } \\
\text { lainnya. }\end{array}$ & 42 & 100 & 32 & 76,2 & $-23,8$ \\
\hline $\begin{array}{l}\text { Memiliki tenaga kesehatan yang dapat dikunjungi } 24 \text { jam untuk keadaan } \\
\text { darurat. }\end{array}$ & 38 & 90,5 & 15 & 35,7 & $-54,8$ \\
\hline
\end{tabular}




\section{PEMBAHASAN}

\section{Perbedaan Tingkat Pengetahuan dengan Pelaksanaan Nagari Siaga}

Pengetahuan mengenai manfaat imunisasi lebih tinggi pada Nagari Kubang Putiah daripada Nagari Padang Laweh yaitu dengan selisih sebesar $45,3 \%$. Seperti penelitian yang dilakukan Sunarti yang dilakukan di Kabupaten Pacitan (2007) yang menyebutkan bahwa pengetahuan tentang imunisasi dasar baik 47,4\% cukup 42,1\%, kurang 10,5\%. Imunisasi merupakan salah satu kegiatan yang didapatkan dari program posyandu. Posyandu sangat penting untuk mengoptimalkan pertumbuhan dan perkembangan balita.Pengetahuan tentang imunisasi diperlukan agar masyarakat terutama ibu membawa balita imunisasi ke posyandu dan fasilitas kesehatan lain. Pengetahuan ini mencakup manfaat imunisasi yaitu agar anak kebal dari penyakit tertentu. Mengurangi penyakit akan meningkatkan kesehatan dan mengoptimalkan pertumbuhan dan perkembangan anak nantinya.

Pengetahuan masyarakat mengenai menu gizi seimbang lebih tinggi pada Nagari Kubang Putiah daripada Nagari Padang Laweh yaitu dengan selisih $28,2 \%$. Masyarakat di Nagari Padang Laweh masih banyak yang kurang mengetahui bahwa buah merupakan salah satu unsur pokok dalam gizi seimbang. Penelitian Khomsan yang dilakukan di Indramayu dan Bogor (2005) menyebutkan bahwa rata-rata nilai pengetahuan gizi di kedua lokasi masih tergolong sedang sehingga masih diperlukan berbagai upaya penyuluhan untuk meningkatkannya. Maksud dari gizi seimbang adalah pola makan yang seimbang antara zat gizi yang diperoleh dari aneka ragam makanan dalam memenuhi kebutuhan zat gizi untuk hidup sehat, cerdas, dan produktif.

Pengetahuan masyarakat mengenai penyakit yang disebabkan oleh rokok lebih tinggi pada Nagari Kubang Putiah daripada Nagari Padang Laweh yaitu dengan selisih sebesar 26,2\%. Rokok dapat

mengakibatkan banyak penyakit yang telah tercantum pada kemasan rokok. Hendaknya masyarakat memperhatikan akibat dari rokok sehingga bisa mengurangi tindakan merokok itu sendiri.

Pengetahuan masyarakat mengenai jarak jamban dan sumber air minum lebih tinggi pada Nagari Kubang Putiah daripada Nagari Padang Laweh yaitu dengan selisih sebesar 26,2\%. Masyarakat di Nagari Padang Laweh belum mengetahui hal tersebut karena masih banyak yang menggunakan jamban umum. Penelitian Sulistyorini di Kota Mojokerto (2005) menyebutkan bahwa faktor pengetahuan tentang syarat jamban sehat berpengaruh terhadap kepemilikan jamban tidak sehat. Kloset atau jamban yang dapat memenuhi syarat kesehatan salah satunya adalah dengan model leher angsa. Menurut Kementrian
Kesehatan, syarat jamban sehat adalah tidak mencemari air, tidak mencemari tanah permukaan, bebas dari serangga, tidak menimbulkan bau, aman digunakan, mudah dibersihkan dan tidak menimbulkan pandangan yang kurang sopan. Diharapkan saat membangun jamban sendiri masyarakat membangun dengan jarak minimal 10 meter dari sumber air bersih.

Pengetahuan masyarakat di Nagari Kubang Putiah masih kurang mengenai pembiayaan kesehatan yang seharusnya dalam pelaksanaan program Nagari Siaga, bahwa dana untuk kegiatan Nagari Siaga berasal dari dana swadaya yang dikumpulkan masyarakat secara rutin. Hal ini disebabkan oleh masyarakat banyak mendapat bantuan dari pihak-pihak dermawan dan pemerintah dalam kegiatan Nagari Siaga selain dengan mengumpulkan iuran yang disebut dana sehat sebesar Rp. 1000,- setiap minggunya. Seperti penelitian Polisiri di Kota Tidore Kepulauan (2007), yang menyebutkan bahwa dana sehat untuk kegiatan Nagari Siaga dikumpulkan secara sukarela oleh masyarakat yang dibayarkan secara rutin untuk melaksanakan kegiatan Nagari Siaga. Sistem pembiayaan kesehatan berbasis masyarakat adalah tatanan yang menghimpun berbagai upaya penggalian, pengalokasian dan pembelanjaan dana yang bersumber dari masyarakat untuk menjamin pemeliharaan kesehatan masyarakat. Bentuk penggalian dana bisa berupa uang sukarela pada saat pertemuan, arisan, pengajian atau tabungan sosial masyarakat dengan jumlah yang sudah disepakati.

Pengetahuan masyarakat mengenai tempat pembuangan tinja yang baik menurut syarat kesehatan lebih tinggi pada Nagari Padang Laweh daripada Nagari Kubang Putiah yaitu dengan selisih sebesar $16,7 \%$. Hal ini disebabkan oleh masih ditemukannya responden di Nagari Kubang Putiah yang belum mengerti mengenai sepenuhnya mengenai syarat tempat pembuangan tinja yang baik dan manfaat dari musyawarah nagari.

\section{Perbedaan Sikap dengan Pelaksanaan Nagari Siaga}

Dalam penelitian ini tidak ditemukan responden yang mempunyai sikap negatif. Penelitian yang dilakukan oleh Puspitawati di Kabupaten Madiun (2007) didapatkan bahwa terdapat hubungan yang bermakna antara hubungan kepuasan masyarakat secara multi atribut dan secara umum terhadap Nagari Siaga. Sikap yang positif akan mempermudah untuk melaksanakan kegiatan Nagari Siaga.

Sikap positif terhadap nilai-nilai kesehatan belum tentu terwujud dalam suatu tindakan nyata. Hal ini disebabkan oleh berbagai alasan, antara lain:

a. Sikap terwujud dalam suatu tindakan yang tergantung pada situasi yang ada pada saat itu.

b. Sikap akan diikuti atau tidak diikuti oleh tindakan yang mengacu kepada pengalaman orang lain. 
c. Sikap diikuti atau tidak diikuti oleh suatu tindakan berdasarkan pada banyak atau sedikitnya pengalaman seseorang.

d. Nilai yang berlaku dalam kehidupan masyarakat dan menjadi pegangan setiap orang dalam melaksanakan kehidupan sosial.

e. Dipengaruhi oleh perilaku orang-orang yang dianggap penting (reference group), misalnya alim ulama, kepala suku, dan sebagainya. Sehingga perilaku tersebut akan dicontoh.

f. Sumber daya (resources) yang mencakup fasilitas, uang, waktu, tenaga, dan sebagainya.

g. Kebudayaan atau pola hidup yang dihasilkan dari perilaku normal, kebiasaan, nilai-nilai, dan penggunaan sumber-sumber di dalam suatu masyarakat.

\section{Perbedaan Tindakan dengan Pelaksanaan Nagari Siaga}

Tindakan masyarakat mengenai pemakaian jamban dengan model leher angsa lebih tinggi pada Nagari Kubang Putiah daripada Nagari Padang Laweh yaitu dengan selisih sebesar $42,8 \%$. Tindakan ini disebabkan oleh masyarakat di Nagari Padang Laweh masih banyak menggunakan jamban bersama yang langsung dibuang pada kolam ikan atau kali. Penelitian yang dilakukan Soamole di Kabupaten Bogor (2004) sebagian besar siswa laki-laki di SMA Negeri 1 Jasinga Kabupaten Bogor memiliki kebiasaan merokok dalam kategori tinggi. Salah satu faktor penyebab kebiasaan merokok adalah terdapat anggota keluarga yang merokok.

Tindakan masyarakat mengenai olahraga secara teratur lebih tinggi pada Nagari Kubang Putiah daripada Nagari Padang Laweh yaitu dengan selisih sebesar $40,5 \%$. Olahraga yang kurang disebabkan oleh pekerjaan masyarakat yang tidak mempunyai waktu untuk olahraga. Menurut pembina Nagari Siaga, kesibukan tersebut juga menyebabkan masyarakat mudah lelah sehingga jarang melakukan olaraga rutin

Tokoh masyarakat yang memberikan contoh teladan tentang hidup sehat lebih tinggi pada Nagari Kubang Putiah daripada Nagari Padang Laweh yaitu dengan selisih sebesar $35,7 \%$. Pada program Nagari Siaga dukungan yang diharapkan dari tokoh masyarakat dapat berupa dukungan moral, dukungan finansial atau dukungan material, sesuai kesepakatan dan persetujuan

masyarakat dalam rangka pengembangan Nagari Siaga.

Tindakan masyarakat mengenai pemberian ASI saja selama 6 bulan lebih tinggi pada Nagari Kubang Putiah daripada Nagari Padang Laweh yaitu dengan selisih sebesar $35,7 \%$. Hal ini disebabkan oleh masyarakat kurang memiliki waktu yang cukup setiap harinya untuk memberikan ASI saja walaupun mereka mengetahui bahwa ASI eksklusif bermanfaat untuk kesehatan bayi. Penelitian Jatmiko yang dilakukan di Yogyakarta (2008) menyebutkan bahwa terdapat hubungan yang bermakna antara pendidikan ibu dengan pemberian ASI eksklusif, dan hubungan yang bermakna antara pendapatan keluarga dengan pemberian ASI eksklusif, serta adanya korelasi positif yang rendah antara pendidikan ibu dan pendapatan keluarga terhadap pemberian ASI eksklusif. ASI memberi semua energi dan nutrisi yang dibutuhkan bayi selama 6 bulan pertama hidupnya. Pemberian ASI eksklusif mengurangi tingkat kematian bayi yang disebabkan berbagai penyakit yang umum menimpa anak-anak seperti diare dan radang paru, serta mempercepat pemulihan bila sakit dan membantu menjarangkan kelahiran.

Tindakan masyarakat yang menguras bak mandi sekali seminggu lebih tinggi pada Nagari Kubang Putiah daripada Nagari Padang Laweh yaitu dengan selisih sebesar 23,8\%. Penelitian Ganie yang dilakukan di Kelurahan Padang Bulan Medan (2009) menyebukan bahwa tindakan responden terhadap pelaksanaan 3M (Mengubur barang bekas, Menutup, dan Menguras tempat penampungan air) sebagian besar adalah sedang. Cara memberantas jentik nyamuk adalah menguras bak mandi secara teratur

Masyarakat yang menggunakan lantai yang bukan dari tanah lebih tinggi pada Nagari Kubang Putiah daripada Nagari Padang Laweh yaitu dengan selisih sebesar $21,4 \%$. Perlu menanamkan pemahaman pada masyarakat bahwa lantai tanah tidak baik bagi kesehatan dan menimbulkan banyak penyakit.

Tenaga kesehatan yang dapat dikunjungi 24 jam untuk keadaan darurat lebih tinggi pada Nagari Padang Laweh daripada Nagari Kubang Putiah yaitu dengan selisih sebesar 54,8\%. Di nagari Kubang Putiah, tenaga kesehatan belum bisa dikunjungi 24 jam karena adanya tugas belajar bagi petugas kesehatan yang menyebabkan Poskesri tutup pada hari tertentu.

Tindakan masyarakat melaporkan kepada petugas kesehatan saat ditemukan masalah kesehatan lebih tinggi pada Nagari Padang Laweh daripada Nagari Kubang Putiah yaitu dengan selisih sebesar sebesar 23,8\%. Hal ini merupakan salah satu indikator keberhasilan Nagari Siaga yaitu berjalannya surveilans berbasis masyarakat. Bagi Nagari Kubang Putiah diperlukan sosialisasi mengenai pentingya pelaporan secara dini saat ditemukan masalah kesehatan agar tidak berkembang menjadi masalah yang serius.

Kebijakan yang perlu diambil untuk optimalnya pelaksanaan Nagari Siaga adalah dengan pengembangan kerjasama tim di masyarakat. Tujuan langkah ini adalah untuk mempersiapkan para petugas, tokoh masyarakat, serta masyarakat agar mereka tahu dan mau bekerjasama dalam satu tim untuk mengembangkan Nagari Siaga. Dalam langkah ini termasuk kegiatan advokasi kepada para penentu kebijakan, agar mereka mau memberikan dukungan, 
baik berupa kebijakan, agar mereka mau memberikan dukungan, baik berupa kebijakan atau anjuran, serta restu, maupun dana atau sumber daya lain, sehingga pengembangan Nagari Siaga dapat berjalan dengan lancar. Sedangkan pendekatan kepada tokoh-tokoh masyarakat bertujuan agar mereka memahami dan mendukung, khususnya dalam membentuk opini publik guna menciptakan iklim yang kondusif bagi pengembangan Nagari Siaga.

Dukungan yang diharapkan dapat berupa dukungan moral, dukungan finansial atau dukungan material, sesuai kesepakatan dan persetujuan masyarakat dalam rangka pengembangan Nagari Siaga. Organisasi yang dimiliki kedua nagari yang merupakan wadah-wadah kegiatan masyarakat di bidang kesehatan seperti, PKK, Persatuan Donor Darah Indonesia (PDDI) serta organisasi kemasyarakatan lainnya, diikutsertakan dalam setiap pertemuan dan kesepakatan untuk program-program Nagari Siaga selanjutnya.

\section{KESIMPULAN}

Terdapat perbedaan yang signifikan mengenai tingkat pengetahuan masyarakat dan tindakan antara Nagari Padang Laweh dan Nagari Kubang Putiah, yaitu lebih tinggi pada Nagari Kubang Putiah. Tidak terdapat perbedaan sikap masyarakat antara Nagari Padang Laweh dan Nagari Kubang Putiah. Pengetahuan masyarakat mengenai fungsi pemimpin dan tokoh masyarakat dalam program Nagari Siaga lebih tinggi pada Nagari Kubang Putiah daripada Nagari Padang Laweh yaitu dengan selisih sebesar $38,1 \%$. Pengetahuan masyarakat tentang oleh siapa sebaiknya persalinan dilakukan lebih tinggi pada Nagari Kubang Putiah daripada Nagari Padang Laweh yaitu dengan selisih sebesar 38,1\%. Pengetahuan masyarakat mengenai fungsi Poskesri lebih tinggi pada Nagari Kubang Putiah daripada Nagari Padang Laweh yaitu dengan selisih sebesar 35,8\%.

\section{SARAN}

Bagi Nagari Padang Laweh agar ditingkatkannya sosialisasi kepada masyarakat mengenai pentingnya kesehatan dan program Nagari Siaga oleh petugas kesehatan dan pemuka masyarakat. Bagi Nagari Kubang Putiah perlu dikembangkan program Nagari Siaga secara terus menerus. Akan tetapi perlu ditempatkan petugas kesehatan yang dapat dikunjungi 24 jam. Bagi kedua nagari untuk lebih meningkatkan partisipasi lintas sektoral antara petugas kesehatan mulai dari petugas kesehatan jorong sampai dengan kabupaten bersama dengan petugas pemerintahan seperti wali nagari, camat dan pendekatan kepada sektor legislatif kabupaten.

Persalinan sebaiknya dilakukan oleh tenaga bidan atau tenaga kesehatan lainnya. Nagari Padang
Laweh memiliki tenaga bidan yang bertempat tinggal di nagari tersebut. Tidak hanya itu, akses angkutan umum ke rumah sakit dan puskesmas kecamatan termasuk mudah sehingga memungkinkan masyarakat untuk melakukan persalinan di tempat penyedia fasilitas kesehatan.

\section{DAFTAR PUSTAKA}

Ane, Loly Rossy. (2009). Evaluasi Pelaksanaan Jorong Siaga di Kecamatan Rao Utara Kabupaten Pasaman Tahun 2009. [Skripsi]. Padang: PSIKM FK Unand.

Depkes RI. (2006). Pedoman Pengembangan Nagari Siaga Panduan bagi Petugas. Jakarta.

Dinas Kesehatan Propinsi Jawa Timur. (2008). Pedoman Pelaksanaan Pengembangan Nagari Siaga di Jawa Timur. Surabaya.

Dinas Kesehatan Propinsi Sumatera Barat. Laporan Tahunan Dinas Kesehatan Propinsi Sumatera Barat Tahun 2008. Padang.

Exclusive Breastfeeding: The Only Water Source Young Infants Need-Frequently Asked Questions[on line]. Dari: www.linkagesproject.org[21 Juni 2010].

Ganie, MA. (2009). Gambaran Pengetahuan, Sikap dan Tindakan tentang 3M (Mengubur barang bekas, Menutup, dan Menguras tempat penampungan air) Pada Keluarga di Kelurahan Padang Bulan Tahun 2009. [Skripsi]. Medan: Universitas Sumatera Utara.

Jatmiko, DI. (2008). Hubungan Pendidikan Ibu dan Pendapatan Keluarga terhadap Pemberian Asi Eksklusif di Puskesmas Kraton, Kecamatan Kraton, Kotamadya Yogyakarta, Propinsi D.I. Yogyakarta. [Skripsi]. Semarang: Universitas Islam Sultan Agung.

Khomsan, A. (2006). Studi Tentang Pengetahuan Gizi Ibu dan Kebiasaan Makan Pada Rumah Tangga Di Daerah Dataran Tinggi Dan Pantai. Jurnal Gizi dan Pangan.

Notoatmodjo, S. (2007). Promosi Kesehatan dan Ilmu Perilaku. Jakarta: Rineka Cipta.

Pegertian Gizi Seimbang dan Meyusun Menu [on line]. Dari: www.repository.ui.ac.id [21 Juni 2010].

Polisiri, M. (2009). Implementasi Nagari Siaga di Kota Tidore Kepulauan. Jurnal KMPK UGM.

Puspitawati. (2007). Tingkat Kepuasan Masyarakat terhadap Nagari Siaga. Madiun: Program Studi Kebidanan Madiun. 
Putri, SA. Hubungan Antara Sikap Tokoh Masyarakat Secara Multiatribut dan Secara Umum Terhadap Pelaksanaan Nagari Siaga (Di Desa

Soamole, I. (2004). Hubungan Antara Sikap Terhadap Merokok Dengan Kebiasaan Merokok Pada Remaja (Penelitian Pada Siswa Laki-Laki Di Sma Negeri 1 Jasinga Kabupaten Bogor Propinsi Jawa Barat Tahun Pelajaran 2004/2005). [Skripsi]. Semarang: Universitas Negeri Semarang.

Sulistyorini, L. (2005). Faktor yang Mempengaruhi Kepemilikan dan Pemakaian Jamban Keluarga yang Memenuhi Syarat di Kota Mojokerto. [Skripsi]. Surabaya: Universita Airlangga.
Sunarti.(2007). Gambaran Faktor yang Mempengaruhi Cakupan Imunisasi Dasar 100\% (Di Wilayah Kerja Puskesmas Tegalombo Kabupaten Pacitan). [Karya Tulis Ilmiah] Surabaya: Poltekkes Depkes Surabaya.

Tujuh Syarat Membuat Jamban Sehat [on line]. Dari: www.sanitasi.or.id [21 Juni 2010]

Waduk Kecamatan Takeran Kabupaten Magetan). (2008). [Skripsi]. Malang: Universitas Muhammadiyah Malang. 